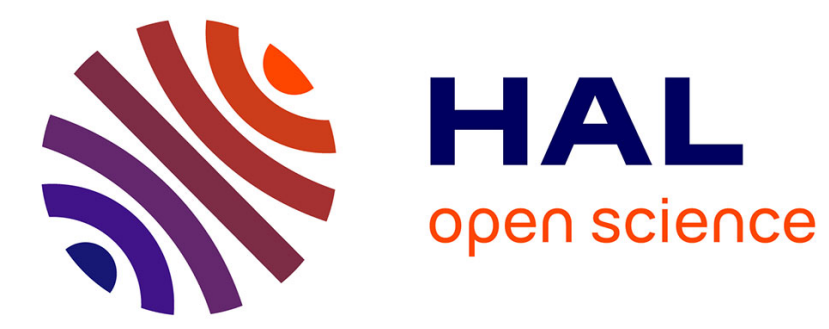

\title{
Quantum well cells for thermophotovoltaics
}

J. Connolly, C Rohr

\section{To cite this version:}

J. Connolly, C Rohr. Quantum well cells for thermophotovoltaics. Semiconductor Science and Technology, 2003, 18 (5), pp.S216-S220. 10.1088/0268-1242/18/5/311 . hal-02635329

\section{HAL Id: hal-02635329 \\ https://hal.science/hal-02635329}

Submitted on 3 Aug 2020

HAL is a multi-disciplinary open access archive for the deposit and dissemination of scientific research documents, whether they are published or not. The documents may come from teaching and research institutions in France or abroad, or from public or private research centers.
L'archive ouverte pluridisciplinaire HAL, est destinée au dépôt et à la diffusion de documents scientifiques de niveau recherche, publiés ou non, émanant des établissements d'enseignement et de recherche français ou étrangers, des laboratoires publics ou privés. 


\title{
REVIEW ARTICLE
}

\section{Quantum Well Cells for Thermophotovoltaics}

\author{
J.P. Connolly and C. Rohr \\ Experimental Solid State Physics, Blackett Laboratory, Imperial College London, \\ SW7 2BW, UK
}

\begin{abstract}
.
Quantum well cells (QWCs) are p - i - n photovoltaic devices with multiple quantum wells (MQWs) inserted in the intrinsic region. They show the desirable characteristic for thermophotovoltaics (TPV) of an easily tuneable bandgap. This is highly relevant because the bandgaps of homostructures are restricted by the range of lattice matched substrates available. As a consequence bulk structures cannot be tuned to desirable narrow band emission spectra. QWCs, however, display tuneable bandgaps from several points of view. Firstly, the MQW band-edge is inherently tuneable by changing well depth and dimension. More significantly, strain compensated MQW systems allow lattice mismatched layers to be deposited without the formation of dislocations. This permits a much greater range of compositions and hence band-gaps than are obtainable with lattice matched systems. We first review the fundamental understanding of spectral response and dark current of the QWC and describe the initial proposal of QWCs for TPV before examining subsequent work on lattice matched InGaAsP/InP. Design limitations of the lattice matched materials can be eliminated by applying strain compensation techniques to strained materials. We show dark current measurements for lattice matched and strained systems with dark currents lower than other promising TPV designs despite longer wavelength absorption edges. This work has recently produced a QWC capable of reaching the Holmia narrow band emission peak at wavelength $1950 \mathrm{~nm}$ which shows the promise of this approach for TPV.
\end{abstract}

PACS numbers: 78.66.Fd, 68.65.+g, 85.60.Bk, 73.61.Ey, 81.05.Ea

\section{Introduction}

The quantum well cell (QWC) is a photovoltaic device with a multiple quantum wells system (MQW) inserted in the intrinsic region of a $\mathrm{p}-\mathrm{i}-\mathrm{n}$ cell [1]. Carriers photogenerated in the quantum wells (QWs) escape with high efficiency thereby enhancing the short circuit current $J_{s c}$ compared to an identical cell without wells known as a barrier control [2]. A bulk cell with the same bandgap as the quantum wells (known as a well control) can absorb the same range of wavelengths and produce a similar $J_{s c}$. However the dark current in such a bulk cell is greater than that of the QWC. As a consequence studies of the dark current have suggested that the $J_{s c}$ increase in QWCs may more than compensate the increase in dark current giving rise to highly efficient cells. 
QWCs have inherent advantages for TPV due not only to better voltage performance but also to a flexible bandedge applicable to long wavelength operation. Each period comprised of wells and barriers can be designed so that the strain in the former is balanced by strain of opposite sign in the latter in a technique known as strain compensation or strain balancing. This allows growth of cells made from material with a much wider range of compositions for which no lattice matched substrates exist.

QWCs are therefore unique in that they can be tailored for a particular incident light spectrum. Finally, these cells show better temperature coefficients of efficiency with temperature than bulk cells which is of particular interest for TPV $[3,4]$.

\section{Fundamental studies}

\subsection{Photocurrent enhancement}

Early work on QWCs [2] looked at solar applications in $\mathrm{Al}_{\mathrm{x}} \mathrm{Ga}_{1-\mathrm{x}}$ As with GaAs QWs and presented modelled experimental quantum efficiency (QE) of such devices showing the increase in $J_{s c}$ due to the presence of wells. The theory explains this by assuming $100 \%$ escape efficiency for carriers photogenerated in the wells. This assumption is reported valid as long as a field is maintained across the wells. The accurate modelling of measured QE confirms the theoretical description of the densities of states in the QWC. This model has been extended to allow for strain effects in the barriers and wells [5] using modelling work to be published.

Serdiukova et al [6] present a model specifically applied to $\operatorname{In}_{\mathrm{x}} \mathrm{Ga}_{1-\mathrm{x}} \mathrm{As} \mathrm{MQWs}$ for TPV looking at strained wells $(\mathrm{x}>0.6)$ kept below their critical thickness. The work presents a QE model together with dark current calculations and does not include experimental data. The model predicts that $J_{s c}$ enhancements of up to a factor of 2 are possible over the bulk $\operatorname{In}_{0.53} \mathrm{Ga}_{0.47} \mathrm{As}$ baseline lattice matched to $\mathrm{InP}$, with efficiency increasing from $4.5 \%$ to $9 \%$ as a result for a $1500 \mathrm{~K}$ blackbody spectrum. It then predicts very high efficiency limits, for example $42 \%$ for a $2000 \mathrm{~K}$ blackbody spectrum though details concerning this upper limit are incomplete.

The two models show essentially similar results for spectral response when compared for the available results published. The main conclusion is that QWs boost $J_{s c}$ significantly in a way which is well understood in lattice matched and strained materials.

\subsection{Dark current}

The QWC shows promise for photovoltaic applications if the increased $J_{s c}$ due to the QWs is not negated by an increase in dark current.

Experimental and theoretical analysis of the electroluminescence (EL) of GaAs/InGaAs and AlGaAs/GaAs single quantum well (SQW) devices has been presented by Nelson [7]. This analysis suggests that the electron and hole quasi-Fermilevel separation $\left(\Delta E_{f}\right)$ in the wells is less than the applied bias by a few tens of meV, whereas in the barriers $\Delta E_{f}$ is equal to the applied bias. In this model the carrier 
concentrations in the wells are lower than expected if carrier populations are described by the applied bias. As a result the reduced recombination and hence dark current suggests that the QWC is an efficient photovoltaic design.

Of particular relevance to TPV is a temperature dependent study for double-well AlGaAs/GaAs QWCs [8]. Significantly, $\Delta E_{f}$ was found to rise with temperature. It is suggested that this is due to thermally assisted escape from the wells under an applied field, and that the dark current will rise less quickly with increasing temperature than bulk cells. Experimental measurement and analysis of photocurrent and photoluminescence data provide evidence for temperature dependent escape in InGaAs/InP [9].

Nelson et al [10] have successfully modelled the dark currents of SQW cells with dark currents dominated by non-radiative recombination in the intrinsic region. The approach outlined in Ref. [10] has been extended to MQWs subject to the depletion approximation [11] where the authors suggest a reduced $\Delta E_{f}$ in the wells to explain the dark currents. Similar results were subsequently found in $\operatorname{In}_{0.53} \mathrm{Ga}_{0.47} \mathrm{As}$ QWCs lattice matched to InP [12]. The value of $\Delta E_{f}$ in these MQW cases was higher than previous work on SQW cells though the authors suggest this is an overestimate due to the depletion approximation.

\section{Lattice matched QWCs applied to TPV}

The application of QWCs to TPV was first proposed by Griffin et al [13] and independently by Freundlich [14].

Griffin has noted that available bulk materials cannot be perfectly matched to available spectra and the application of QWCs is suggested, since the bandgap is readily tuneable by adjusting the dimensions of the QWs and their depth. Two QWC systems were studied. The first (QWC-A) comprised $15 \mathrm{In}_{0.53} \mathrm{Ga}_{0.47} \mathrm{As}$ wells, the second (QWCB) 60 quaternary $\operatorname{In}_{\mathrm{x}} \mathrm{Ga}_{1-\mathrm{x}} \mathrm{As}_{\mathrm{y}} \mathrm{P}_{1-\mathrm{y}}$ wells, both lattice matched to InP. When compared to a double-heterostructure control with an $\mathrm{In}_{0.53} \mathrm{Ga}_{0.47} \mathrm{As}$ i layer under a simulated Ytterbia spectrum, QWC-A showed an increase in $V_{o c}$ by a factor of 1.7. QWC-B was compared to QWC-A and showed an increase in $J_{s c}$ by a factor of 2.4, and no significant loss in $V_{o c}$.

Further work has examined QWCs for TPV in quaternary $\operatorname{In}_{\mathrm{x}} \mathrm{Ga}_{1-\mathrm{x}} \mathrm{As}_{\mathrm{y}} \mathrm{P}_{1-\mathrm{y}}$ lattice matched to $\mathrm{InP}$ [15]. The QWC is compared to another promising technology which is the monolithic-interconnected-module (MIM) design. Although the QWC bandgap is slightly greater than the InGaAs MIM cell, it is found that the QWC dark current is orders of magnitude lower (see figure 1).

This leads to predicted efficiencies of the QWC being better than that of the bulk InGaAs MIM and bulk GaSb under many spectra as indicated in table 1 assuming a back surface reflectivity of $100 \%$ (see below).

As these QWCs also perform well under solar illumination it is suggested they could be used in hybrid solar-TPV systems [15]. 


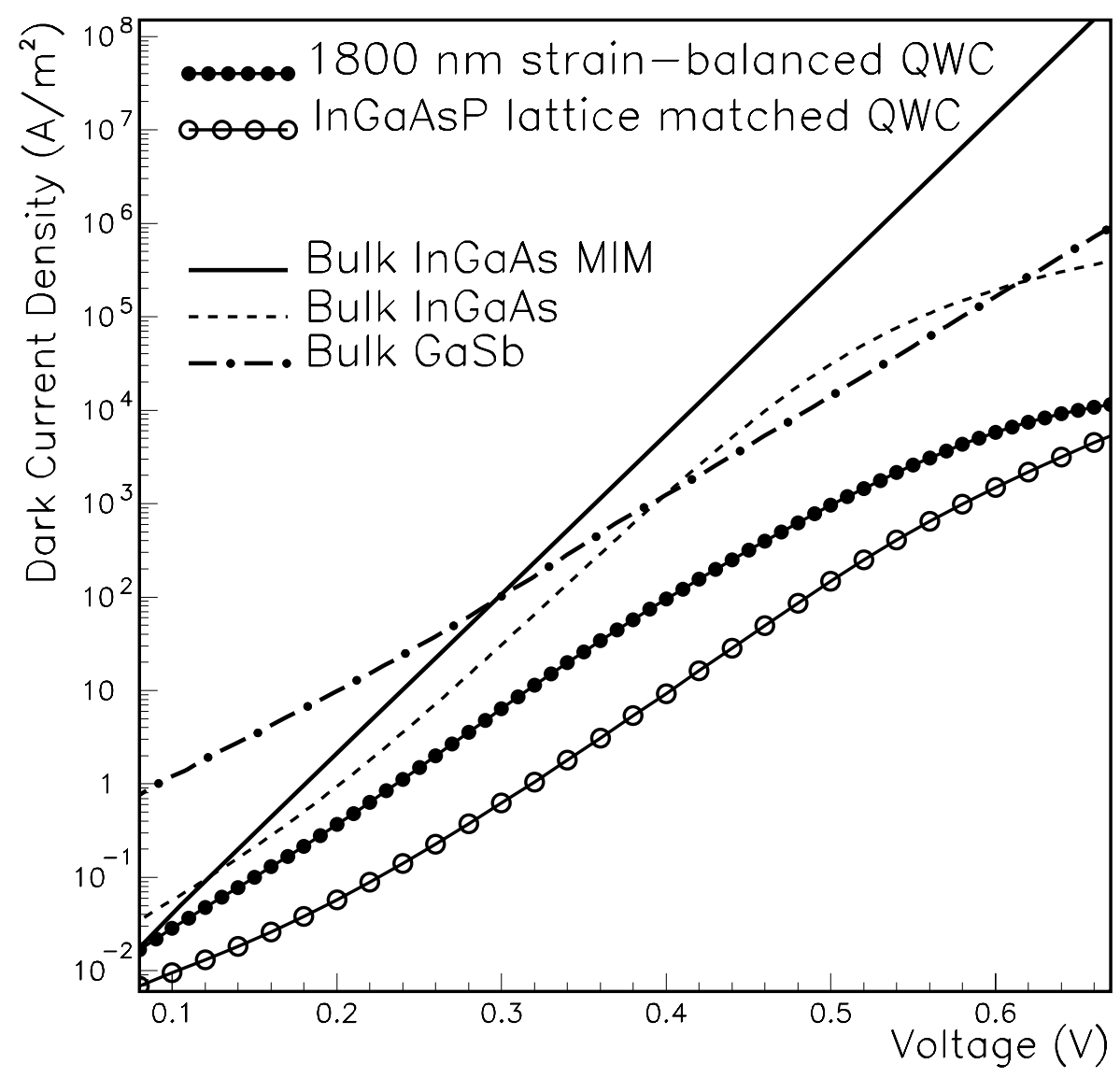

Figure 1. Dark current comparison for lattice-matched and strain-balanced QWC, bulk InGaAs, and GaSb

\section{Strain compensated cells}

The longest wavelength absorption edge possible with the lattice matched system is about $1700 \mathrm{~nm}$ corresponding to $\operatorname{In}_{0.53} \mathrm{Ga}_{0.47}$ As. However smaller bandgaps are required for lower temperature operation with selective emitters such as Thulia or Holmia having a peak emission at about $1750 \mathrm{~nm}$ and $1950 \mathrm{~nm}$ respectively. Figure 2 shows the progress in extending the spectral response of the QWC compared with bulk lattice matched $\mathrm{In}_{0.53} \mathrm{Ga}_{0.47} \mathrm{As}$ as described in this section.

\subsection{Strain balancing}

A subsequent approach to reach longer wavelengths than obtainable with lattice matched material has been investigated. This is the concept of strain compensation or strain balancing $[18,19]$ and should take elastic constants into account, particularly if the strain is high. In a multilayer structure, lattice mismatched layers can be grown with 


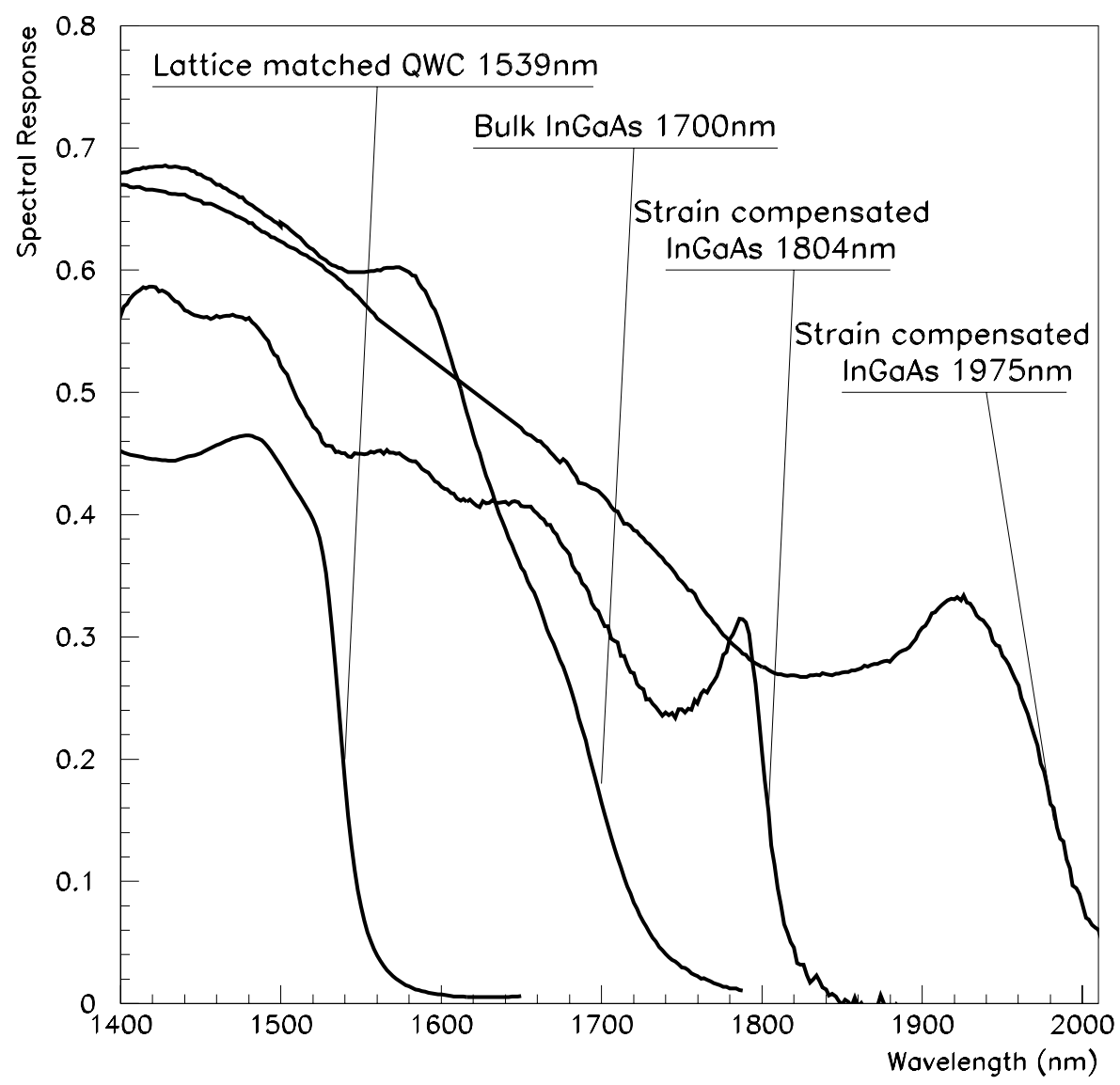

Figure 2. Quantum efficiency data for a bulk $\operatorname{In}_{0.53} \mathrm{Ga}_{0.47} \mathrm{As}$ cell, lattice matched QWC and two strain compensated QWCs showing the progressively longer wavelength bandedges achieved.

alternating tensile and compressive strain. If the growth is such that the stress at successive interfaces is opposite in sign and equal then an arbitrary number of periods can be grown. For highly strained materials the strain energy must be kept below a critical value, however, to avoid the onset of three-dimensional growth [20]. This constraint and its consequences for well composition and dimensions limit the extension of absorption to about $2100 \mathrm{~nm}$.

In practice the stress balancing puts stringent requirements on growth. Although these practical reasons set a limit on the number of multilayer periods, the structure is primarily constrained by background doping which limits the maximum i region width which can sustain a built in field. 


\begin{tabular}{lccccc}
\hline Spectrum & $\begin{array}{c}\text { InGaAs } \\
\text { MIM }\end{array}$ & $\begin{array}{c}\text { bulk } \\
\text { GaSb }\end{array}$ & $\begin{array}{c}\text { InGaAsP } \\
\text { QWC }\end{array}$ & $\begin{array}{c}1770 \mathrm{~nm} \\
\text { QWC }\end{array}$ & $\begin{array}{c}2100 \mathrm{~nm} \\
\text { QWC }\end{array}$ \\
\hline AM1.5G (100x) & 16 & 16 & 20 & 17 & 23 \\
2000K blackbody & 11 & 11 & 12 & 13 & 17 \\
1500K blackbody & 5.0 & 5.6 & 4.8 & 6.6 & 10 \\
MgO emitter & 13 & 15 & 16 & 22 & 29 \\
Erbia (1500nm filter) & 37 & 37 & 46 & 42 & 34 \\
Holmia & 4.5 & 5.4 & 4.1 & 6.6 & 24 \\
\hline
\end{tabular}

Table 1. Comparison of predicted efficiencies (in \%) of lattice-matched bulk InGaAs MIM, GaSb, a lattice-matched InGaAsP QWC, and a $1770 \mathrm{~nm}$ and a modelled $2100 \mathrm{~nm}$ strain-compensated QWC with simulated back-mirror and zero front surface reflectivity, under various spectra normalised to $100 \mathrm{~kW} / \mathrm{m}^{2}$, and $5 \%$ grid shading $[16,17]$.

\subsection{Development}

Rohr et al [21] have presented a successful MQW grown in this manner but balancing the strain without accounting for the different elastic constants in barriers and wells. This work presents modelling comparing the strain compensated QWC with the $\operatorname{In}_{\mathrm{x}^{-}}$ $\mathrm{Ga}_{1-\mathrm{x}} \mathrm{As}_{\mathrm{y}} \mathrm{P}_{1-\mathrm{y}}$ QWC reviewed above, a GaSb and again a MIM device. Comparisons under a wide range of spectra including solar, black body and narrow band emission spectra are given in table 1.

In all cases the predicted QWC result outperforms the bulk devices. Under some spectra the earlier lattice matched design shows efficiencies higher than the strain compensated design because of the bandgap of the latter being lower than that required to match the relevant spectrum. Overall this work suggests that a strain balanced QWC with appropriately designed band structure is equal or superior to lattice matched QWCs and to bulk devices.

Experimental results [5] support this and extend the balancing by taking account of material elastic stiffness constants. The device grown extends response to slightly longer wavelength than GaSb and significantly further than the InGaAs MIM design. In this case however the QWC result is extrapolated for optimisations. These are reasonable, consisting of using the model to fit the experimental QE and applying an anti-reflection coat and a planar reflecting back surface subsequently seen in other samples $[22,23]$ as discussed below.

The extended response of the strain compensated QWC again outperforms MIM and GaSb cells in all spectra (see table 1). This is mainly due to the lower measured dark current [5]. The lattice matched QWC is preferable however in solar and higher energy spectra such as Ytterbia because of its higher bandgap, consistent with the original aim of extending the spectral response of the QWC. 


\subsection{Optimisation for Thulia (1750nm)}

Device optimisation has been considered with the initial requirement that the spectrum should be at a moderate temperature which is more desirable from a systems point of view. This means that QWC design has concentrated on extending the long wavelength response to match long wavelength narrow band emitter spectra.

Whereas the early work concentrated on black body, Ytterbia and Erbia spectra, a desire to allow lower temperature combustion has moved attention to Thulia (emission centred on 1750nm) and Holmia (1950nm) spectra.

The strain compensation methodology has been extended to account for the different elastic properties of barriers and wells [19]. Comparisons presented by Abbott [23] examine the performance of bulk InGaAs and of QWCs with progressively lower QW bandgaps.

The successful growth and characterisation of a stress balanced QWC comprising 40 wells and extending absorption to $1950 \mathrm{~nm}$ which covers the Thulia spectrum adequately is reported [23]. Transmission electron microscopy (TEM) measurements reveal no visible dislocations originating from the highly strained barriers and wells showing that the stress compensation technique is applicable to a large number of QW periods.

Concerning dark currents, a more moderately strained QWC comprising 30 strain compensated $\operatorname{In}_{0.62} \mathrm{Ga}_{0.38}$ As wells with an absorption edge at $1800 \mathrm{~nm}$ has a dark current below that of the lattice matched bulk $\operatorname{In}_{0.53} \mathrm{Ga}_{0.47} \mathrm{As} \mathrm{p}-\mathrm{i}-\mathrm{n}$ cell $[5,23]$. While the dark current of the highly strained QWC is higher the authors suggest that this may be partly due to poor quality overgrowth and surface morphology despite the good QW interface quality as shown by the TEM measurements.

Furthermore, reflection from the metallic contact on the back surface plays a significant role in the spectral response of these cells [22]. The effect is very significant for these structures, since the thin MQW layers cannot absorb all the incident light with a single pass and the number of MQW periods is constrained by the limits imposed on practical i region widths due to unintentional background doping. It follows that light trapping techniques are particularly relevant to these structures. The effectiveness of this technique can easily be improved, and should readily attain reflectivities approaching $100 \%$ instead of the $65 \%$ observed with appropriate choice of substrates and processing steps to ensure a specular back surface.

Three different indications suggest that the back surface reflectivity is about $65 \%$ in the case of Ref. [22]. Firstly, direct reflectivity measurements appear significantly higher than expected for InP below the bulk and QW bandgaps. Secondly, a multilayer analysis was applied and requires the same back reflectivity to reproduce experimental results. Finally, modelling of the QE including internal reflections requires the same value to reproduce the measured QE in all three samples.

All three cells have similar bulk response although the 30 well QWC is slightly lower. The efficiency under a Thulia spectrum increases from $11 \%$ for the lattice matched bulk InGaAs p - i - n to $13.3 \%$ for the $1800 \mathrm{~nm} 30$ QW sample and then to $18.1 \%$ for the 40 
QW sample with a bandedge at $1975 \mathrm{~nm}$ despite its relatively poor dark current.

\subsection{Optimisation for Holmia (1950nm)}

The response of the QWC has been extended to wavelengths suitable for systems based on the Holmia emitter which has an emission peak at about 1950nm. In this case the barriers and wells are more highly strained laying higher demands on growth accuracy. A two well sample has been successfully grown and characterised [24] with a composition of about $74 \%$ indium in the wells resulting in strain at about $+1.44 \%$.

TEM measurements again show sharp MQW interfaces, and atomic force microscopy measurements show surface morphology within tolerances. The MQW widths are shown to be above their nominal widths but within their critical thicknesses.

Cathodoluminescence measurements show a peak at $2040 \mathrm{~nm}$ which is consistent with the modelled QE, confirming the accurate description of the MQW band-edges in the modelling. It has therefore been shown that strain compensation can extend the absorption edge beyond $2000 \mathrm{~nm}$.

Carrier escape studies have been performed on lattice matched InGaAs QWCs [9]. For this highly strained 2 QW sample similar studies show that not all the photogenerated carriers are collected, contributing to poor electrical performance under illumination [24]. The carrier collection improves with increasing temperature, although it is shown to remain incomplete at $100^{\circ} \mathrm{C}$. The authors speculate that transport problems could be partly responsible. By contrast, in the strain compensated QWC with 40 QWs and an absorption edge of $1975 \mathrm{~nm}$ described above, efficient carrier escape has been observed at room temperature and around zero to modest forward bias $[23]$.

\section{Conclusions}

The work reviewed has shown that the QWC shows desirable characteristics for TPV applications.

Firstly, two methodologies have shown that QWCs show promising voltage behaviour, and studies have shown that carrier escape from the wells is in general good. Of relevance here is the temperature studies carried out to date detailing advantages in the QWC design for operation at higher temperatures.

Secondly, and perhaps more importantly, the QWC design is unique in allowing the bandgap to be tailored and hence making it possible to optimise the spectral matching between TPV cell and light spectrum. This is because the well/barrier lattice opens the possibility of growing strained layers on available substrates.

Work on this design has shown promising results. QWCs have demonstrated dark currents lower than relevant bulk cells with comparable or higher bandgaps. As a result, efficiencies projected for the QWC in a range of spectra are higher than available bulk alternatives. 
The $J_{s c}$ of the QWC to date is constrained by the limited number of periods that can be grown because of restrictions on the i region width. Evidence of light reflections suggest a solution to this issue through having more than one light pass. This phenomenon should be easily optimised by a combination of choice of substrates and processing steps ensuring back reflectivities approaching $100 \%$ and structural light trapping schemes ensuring multiple light passes through the structure.

We conclude that the application of the QWC to TPV applications shows promise because of the temperature, voltage, and variable absorption edge characteristics of this design.

\section{References}

[1] Barnham K W J and Duggan G 1990 A new approach to high-efficiency multi-band-gap solar cells J.Appl.Phys 67 3490-3493

[2] Paxman M, Nelson J, Braun B, Connolly J, Barnham K W J, Foxon C T and Roberts J S 1993 Modeling the spectral response of the quantum well solar cell J.Appl.Phys $\mathbf{7 4} 614-621$

[3] Rohr C 2000 InGaAsP Quantum Well Cells for Thermophotovoltaic Applications Ph.D. thesis Imperial College, University of London, http://www.ic.ac.uk/ q- pv/carsten/thesis.pdf

[4] Ballard I, Barnham K W J, Connolly J P, Nelson J, Rohr C, Roberts C, Roberts J and Button C 2001 The effect of temperature on the efficiency of multi quantum well cells for solar and thermophotovoltaic applications Proc. 17th European Conf. and Exhibition on PV Solar Energy, Munich (Munich: WIP and Florence: ETA) pp 41-44

[5] Rohr C, Connolly J, Barnham K W, Mazzer M, Button C and Clark J 2000 Strain-balanced $\mathrm{In}_{0.62} \mathrm{Ga}_{0.38} \mathrm{As} / \mathrm{In}_{0.47} \mathrm{Ga}_{0.53} \mathrm{As}(\mathrm{InP})$ quantum well cell for thermophotovoltaics Proc. 28th IEEE Photovoltaic Specialists Conf., Anchorage (USA: IEEE) pp 1234-1237

[6] Serdiukova I, Newman F, Aguillar L, Vilela M F, Monier C and Ferundlich A 1997 Strained $\mathrm{In}_{0.53} \mathrm{Ga}_{0.47} \mathrm{As} / \mathrm{In}_{x} \mathrm{Ga}_{1-x} \mathrm{As}(x>0.6)$ multiquantum well thermophotovoltaic converters Proc. 26th IEEE PV Specialists Conf. (USA: IEEE) pp 963-966

[7] Nelson J, Barnes J, Ekins-Daukes N, Kluftinger B, Tsui E, Barnham K W J, Foxon T, Cheng T and Roberts J S 1997 Observation of suppressed radiative recombination in single quantum well p-i-n photodiodes J.Appl.Phys. 82 6240-6246

[8] Kluftinger B, Barnham K, Nelson J, Foxon T and Cheng T 2000 Temperature-dependent study of the quasi-Fermi level separation in double quantum well p-i-n structures Microelectronic Engineering 51-52 265-274

[9] Zachariou A, Barnes J, Barnham K W J, Nelson J, Tsui E S M, Epler J and Pate M 1998 A carrier escape study from InP/InGaAs single quantum well solar cells J.Appl.Phys. 83 877-881

[10] Nelson J, Ballard J, Barnham K W J, Connolly J, Roberts J S and Pate M 1999 Effect of QW location on quantum well solar cell dark currents J.Appl.Phys. 86 5898-5905

[11] Connolly J P, Nelson J, Barnham K and Ballard I 2000 Multiple quantum well solar simulator Proc. 28th IEEE PV Specialists Conf., Anchorage (USA: IEEE) pp 1304-1307

[12] Connolly J P, Nelson J, Ballard I, Barnham K W J, Rohr C, Button C, Roberts J and Foxon T 2001 Modelling multi quantum well solar cell efficiency Proc. 17th European Conf. and Exhibition on PV Solar Energy, Munich (Munich: WIP and Florence: ETA) pp 204-207

[13] Griffin P, Ballard I, Barnham K, Nelson J, Zachariou A, Epler J, Hill G, Button C and Pate M 1997 Advantages of quantum well solar cells for TPV Thermophotovoltaic Generation of Electricity: Third NREL Conf., Colorado Springs, AIP Conf. Proc. vol 401 ed T J Coutts et al. (Woodbury, New York: American Institute of Physics) pp 411-422

[14] Freundlich A and Ignatiev A 2000 Quantum well thermophotovoltaic energy converter US Patent $6,150,604$ 
[15] Rohr C, Connolly J P, Barnham K W J, Griffin P R, Nelson J, Ballard I, Button C and Clark J 1999 Optimisation of InGaAsP quantum well cells for hybrid solar-thermophotovoltaic applications Thermophotovoltaic Generation of Electricity: Fourth NREL Conf., Denver, AIP Conf. Proc. vol 460 ed T J Coutts et al. (Woodbury, New York: American Institute of Physics) pp 83-92

[16] Rohr C, Connolly J, Barnham K W, Mazzer M, Button C and Clark J 2000 Strain-balanced InGaAs/InP quantum well cells for thermophotovoltaics Proc. 16th European Photovoltaic Solar Energy Conf. (London: James \& James) VA2.21

[17] Rohr C, Connolly J P, Ekins-Daukes N, Abbott P, Ballard I, Barnham K W, Mazzer M and Button C 2002 InGaAs/InGaAs strain-compensated quantum well cells for thermophotovoltaic applications Physica E: Low-dimensional Systems and Nanostructures 14 158-161

[18] Ekins-Daukes N, Barnham K, Connolly J, Roberts J, Clark J, Hill G and Mazzer M 1999 Strainbalanced GaAsP/InGaAs quantum well solar cells Appl.Phys.Lett 75 4195-4197

[19] Ekins-Daukes N, Kawaguchi K and Zhang J 2002 Strain-balanced criteria for multiple quantum well structures and its signature in X-ray rocking curves Crystal Growth \&3 Design 2 287-292

[20] Nasi L, Ferrari C, Lazzarini L, Salviati G, Tundo S, Mazzer M, Clarke G and Rohr C 2002 Extended defects in InGaAs/InGaAs strain-balanced multiple quantum wells for photovoltaic applications Journal of Physics: Condensed Matter 14 pp. 13367-73

[21] Rohr C, Barnham K W J, Connolly J P, Nelson J, Button C and Clark J 2000 Potential of InGaAsP quantum well cells for thermophotovoltaics Proc. 26th Int. Symposium on Compound Semiconductors, Berlin, Institute of Physics Conf. Series no 166 (Bristol and Philadelphia: Institute of Physics Publishing) pp. 423-426

[22] Abbott P, Rohr C, Connolly J P, Ballard I, Barnham K, Ginige R, Corbett B, Clarke G, Bland S W and Mazzer M 2002 A comparative study of bulk InGaAs and InGaAs/InGaAs strain-compensated quantum well cells for thermophotovoltaic applications Proc. 29th IEEE PV Specialists Conf., New Orleans (USA: IEEE) pp. 1058-61

[23] Abbott P, Rohr C, Connolly J P, Ballard I, Barnham K W, Ginige R, Clarke G, Nasi L and Mazzer M 2002 Characterisation of strain-compensated InGaAs/InGaAs quantum well cells for TPV applications The Fifth Conf. on Thermophotovoltaic Generation of Electricity, Rome, AIP Conf. Proc. vol 653 ed T J Coutts et al. (Woodbury, New York: American Institute of Physics) pp 213-21

[24] Rohr C, Abbott P, Ballard I, Connolly J P, Barnham K W, Nasi L, Ferrari C, Lazzarini L, Mazzer $\mathrm{M}$ and Roberts J 2002 Strain-compensated ingaas/ingaas quantum well cell with $2 \mu \mathrm{m}$ band-edge The Fifth Conf. on Thermophotovoltaic Generation of Electricity, Rome, AIP Conf. Proc. vol 653 ed T J Coutts et al. (Woodbury, New York: American Institute of Physics) pp 344-53 